\title{
High Voltage Pulse Cable and Connector Experience in the Kicker Systems at SLAC *
}

\author{
K. Harris, M. Artusy, A. Donaldson, T. Mattison \\ Stanford Linear Accelerator Center, Stanford CA 94309
}

\section{Abstract}

The SLAC 2-mile linear accelerator uses a wide variety of pulse kicker systems that require high voltage cable and connectors to deliver pulses from the drivers to the magnet loads. Many of the drivers in the SLAC kicker systems use cable lengths up to 80 feet and are required to doliver pulses up to $40 \mathrm{kV}$, with rise and fall times on the order of $20 \mathrm{~ns}$. Significant pulse degradation from the cable and connector assembly cannot be tolerated. Other drivers are required to deliver up to $80 \mathrm{kV}, 20 \mu \mathrm{s}$ pulscs over cables 20 feet long. Scveral combinations of an applicable high volage cable and matching connector have been used at SLAC to determine the optimum assembly that moets the necessary spocifications and is reliable.

\section{SLAC KICKER SYSTEMS}

There are a total of seven conlinuously operating kicker systems currently in use in the SLAC Linear Collider (SLC, divided into three basic types, LC discharge kickers (for Final Focus,) Fermi-type long-pulse cable kickers, and Blumlein short-pulse kickers [1] - [4]. The primary use of the kickcrs are for injection and extraction of the $\mathrm{e}$ - and $\mathrm{e}+$ bunches into the SLC damping rings, to divert $\mathrm{e}$ - bunches to produce e+ bunches, and to dump the beams at the final focus points. The long-pulse kickers are located in the e-north damping ring, and the short-pulse kickers are located in the e+ south damping ring and at the e+ target area, and the LC discharge kjckers are for beam dumping at the final focus area. The SLC kickers systems and damping rings are described in detail in several other papers being presented at the 1991 IEEE Particle Accelerator Conference [4], [5], [7].

\section{OLD KICKER CABLES AND CONNECTORS}

The SLC damping ring and e+ source kickers, as previously described, are divided into two types. Figure 1 [1] shows the Blumlein short-pulse type and Figure 2 shows the Cable long-pulse type. Several types of high voltage pulse cables and connectors/connections have been used in the kicker systems at SLAC. The short-pulse kicker systems (South

\footnotetext{
* Work supported by US Department of Energy contract DE-ACO3. 76SF00515
}

Damping Ring, or SDR, and the et source kicker) have historically used RG-220 cable that has had the outer braid terminated outside and the polyethylene tapered and terminated inside the oil Blumlein. The cables come out of the Blumlein horizontally, and there have been failures due to the air space between the outer braid and the poly as well as the awkward mechanical support of the cable.

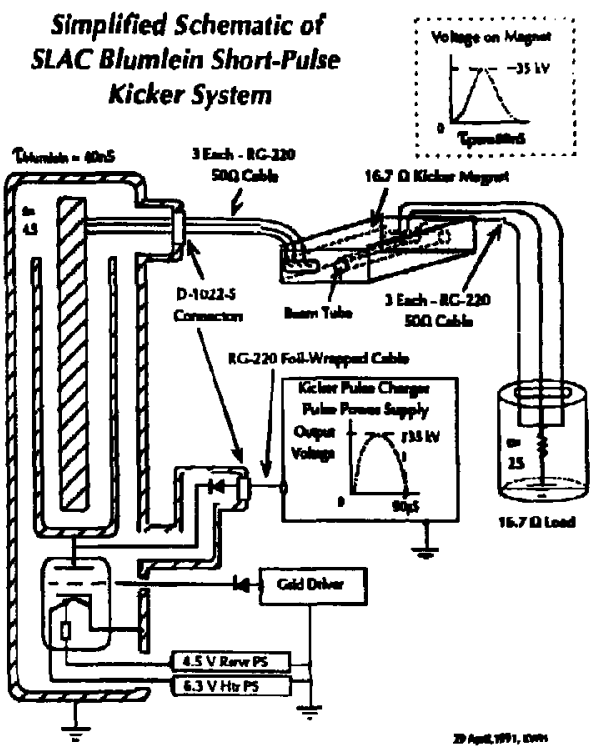

Figure 1. Short-Pulse Blumlein Kicker System.

: The three cables from the Blumlein to the short-pulse kicker magnets are connected to Hugin contact bands in the magnet center conductor slab, with the ground braids clamped to cylinders on the magnet ouler conductor surface. Originally the cable insulation was inserted into a cafvity, formed in the RTV during magnet potting [6], without any preparation, but these connections had a high failure rak. Delrin plastic insens are now potued into the ends to accept the cable insulation, which is tapered and greased to form an air-free connection. There have been no Delrin insen failure s although there has been some corona damage. There have alsu been some failurcs in the RG.220 cables near the magnet where the ground braid

Presented at IEEE Particle Accolcrator Confercnce, San Fancisco. CA, May (j-9,1991 
has separated from the polyethylene allowing corona undemealh,

The long-pulsc kicker systems shown in Figure 2 (North Damping Ring, or NDR) have used Felton \& Guilleaume (F\&G) type HP 10.4/39.0 -50 $/ 60 \mathrm{kV}$ coax that was very robust but difficult to obtain and quite large in diameter. RG220 has also been used, with several lypes of connections. The pulsed-charger [8] cable between the thyratron tank and the pulse-charger sees $=70 \mathrm{kV}$ pulses with rise-times on the order of 20 Hs. The standard connection has been a tapered RG-220 fced-through with o-ring seal around the PVC jacket that allows oil from the thyratron tank to wick inlo the outer braid. This virtually eliminates the air voids between the polyethylene and the braid, which tend to be the primary source of cable failures. The physical connection of the RG-220 to the pulse-charger tank, howcyer, is made at a slightly upward angle, and the outer braid is terminated outside the tank. There is a short length of cable connection that is dry and exposed. This has resulted in several cable failures.

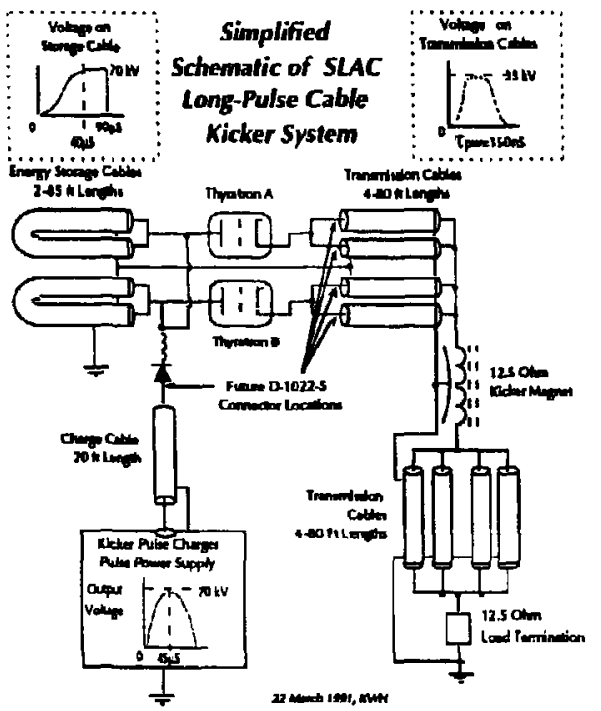

Figure 2. Long-Pulse Cable Kicker System.

The remaining long-pulse cables are currenty RG-220 that are oil filled due to the just described connections. Problems associated with the cables are that oil filling is difficult, very messy, and there are almost always oil lcaks from the cable that have to be dealt with. The Fermi magnets [5] associated with the long-pulsc kickers are connected with four RG-220 cables at each end, with tapered and greased insulation fitting into a tapcred cavity in the RTV potting of the magnet. The cable center conductors angle in to the tapered ends of the magnct center conductor and are held by setscrews accessible through holes in the R'rV that are later filled with greasc. There have been some failures associated with the setscrew arrangement. The cable ground braids are clamped to tubes al the magnet ends. There have been some failures dus to center conductor eccentricity because the cable polyethylene gets warm from the magnet heaters and iends to flow, and the cables enter the magnet from awkward angles with tight bends.

\section{NEW CABLES AND CONNECTORS}

Due to the Blumlein cable failures, an effort was made to develop a cable/connector system that was robust, reliable, compact, and as close to $50 \Omega$ as possible for pulses up to $80 \mathrm{kV}$. Fermi and others [9], [10] have done ex tensive work on improving pulse coax, especially the RG.220 type. Currently, SLAC has Times AA-6778 cable installed in the short-pulse kickers between the pulse-charger and the Blumlcin. AA-6778 is a version of RG-220 that has an Aluminum foil tape layer helween the poly and the outer braid. This foil layer helps reduce the air pockets that cause many cable failures. Working in conjunction with Isolation Designs of Sunnyvale, CA, SLAC developed the D-1022-5 connector for foil-wrapped RG-220 cable. The D-1022-S has an intograted high-voltage (HV) shield to ground to reduce field enhancement [11], oil tight Hugin type multi-lam connectors, and a tapered section for void-free poly fit. The D-1022-S is shown in Figure 3. The D-1022-S was designed using MacPoisson, a relaitveiy simple Finite Element Analysis code on the Macintosh. The maximum field-enhancement in the connector is about $20 \%$.

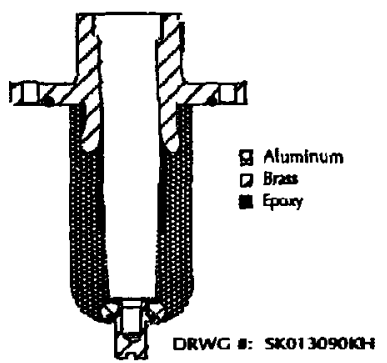

Figure 3. D-1022-S Connector for foil-wrapped RG-220.

The short length of the connector, balanced with the compromise for voltage hold-off capability, serves to preserve the coaxial impedance as much as possible, which can be important for fust pulse systems. The tapered section allows the greased (Dow-Coming 5 Compound) poly section of cable being inserted to force air bubbles out and around the poly. The cable braid is capturced inside a SLAC modified UG-156 connector that is threaded onto the D-1022-S. The most probable weak link in this system is the UG-156 connector 
section. Also, the eccentricity of the RG-220 typo cable is very important for this connector, as is the calibration of the "pencil-sharpener" tool used to taper the poly. SLAC experience has shown that standard RG-220 cable is seldom the same size from batch to batch from most manufacturers, which has led to some problems with cable replacement.

\section{CABLE AND CONNECTOR TESTS}

The D-1022-S connecwr and the associated AA-6778 coax were initially tested on the outpul of the pulse-charger at voltages between $72 \mathrm{kV}$ 10 $88 \mathrm{kV}$ for $=10^{8}$ shots. The output of the cable was unterminated, but a corona [12] ring was installed and the end was mounted in an oil tank. Table I summarizes the test resulis.

Table 1

D-1022-S connector and Times AA-6778 cable slow pulse tests.

\begin{tabular}{|c|c|c|c|c|c|c|}
\hline \multirow{7}{*}{$\square$} & Voluage & \multicolumn{2}{|c|}{ Rep-Rate } & \multicolumn{2}{|c|}{ Tocal Hours } & \\
\hline & $72 \mathrm{kV}$ & \multicolumn{2}{|c|}{$60 \mathrm{~Hz}$} & \multicolumn{3}{|c|}{18} \\
\hline & $75 \mathrm{kV}$ & \multicolumn{2}{|c|}{$120 \mathrm{~Hz}$} & \multicolumn{3}{|c|}{75.16} \\
\hline & $80 \mathrm{kV}$ & \multicolumn{2}{|c|}{$60 \mathrm{~Hz}$} & \multicolumn{3}{|c|}{36} \\
\hline & $80 \mathrm{kV}$ & \multicolumn{2}{|c|}{$120 \mathrm{~Hz}$} & \multicolumn{3}{|c|}{36} \\
\hline & $80 \mathrm{kV}$ & \multicolumn{2}{|c|}{$180 \mathrm{~Hz}$} & \multicolumn{3}{|c|}{69} \\
\hline & $88 \mathrm{kV}$ & \multicolumn{2}{|c|}{$180 \mathrm{~Hz}$} & \multicolumn{3}{|c|}{$0.0167 *$} \\
\hline $\begin{array}{c}\text { Max } \\
\text { Voltage }\end{array}$ & Max PRR & HV Hrs & Tota & al Shots & \begin{tabular}{|c|} 
Rise \\
Time
\end{tabular} & $\begin{array}{l}\text { Pulse } \\
\text { Width }\end{array}$ \\
\hline $88 \mathrm{kV}$ & $180 \mathrm{~Hz}$ & 234.18 & 1.04 & $45 \times 10^{8}$ & $17 \mu \mathrm{s}$ & $=50 \mu \mathrm{s}$ \\
\hline
\end{tabular}

* The pulse charger failed at $88 \mathrm{kV}$.

The cable connector assemblies were also tested on a $60 \mathrm{~Hz} \mathrm{AC}$ corona generator [13]. The plimary testing was for corona inception voltage. Short lengths of AA-6778 cable were terminaled on both ends with the D-1022-S connector, with the end of the connector immersed in oil and terminated with a corona ball of suitable diameter. Corona inception began at about $20.5 \mathrm{kV}$ at the 10 pico-coulomb (pi) level. This agrees well with the MIL C-17 [14] rating of $21 \mathrm{kV}$ of the AA -6778 cable. Raising the vollage to $\approx 22.8 \mathrm{kV}$, corona activity jumped to the $300 \mathrm{pc}$ level. With a connector from one end of the cable removed, corona inception was at $=18.6 \mathrm{kV}$. Various mechanical stresses were induced on the cable assembly, after which the inception point dropped to $\approx 13.6 \mathrm{kV}$. The assemblies also survived high-potting to $100 \mathrm{kV}$.

The D-1022-S connector was then tested by itself in a fixture designed to eliminate the cablc corona from marring the connector corona results. Corona inception of the D-1022-S began at about $37 \mathrm{kV}$. At $38.6 \mathrm{kV}$, the level was in the 15 to $20 \mathrm{pc}$ range, and Ilashover began al nearly $39 \mathrm{kV}$, which was most Jikely the breakdown point of the transformer oil being used in the tests.

\section{CONCLUSIONS}

The new cable connector assemblies being installed at SLAC will enhance maintainability and reliability. Great care in cable/connecter assembly is extremely important for good results. The MII C-17 specification (under which AA-6778 falls) for HV coax cable appears to be sufficient for SLAC's uses. The D-1022-S/AA-6778 assemblies appear to have a high corona inception point, although more data is required. There are plans to install the D-1022-S connectors between the pulse-charger and the thyratron tank, and to and from the new pulse tuners in series with the 80 ft transmission cables.

Special Thanks to: Don Amett, Don Williams, John Kraszczak, Piotr Blum, Raghib Haqq. Jim Cundiff, Clive O'Conner, John Rock, Steve Pearce, and Pat Banglos of SLAC and Joscph Bianco of Isolation Designs, Sunnyvale, $\mathrm{CA}$ for their effor in the design, manufacturing, and lesting of the described equipment.

\section{REFERENCES}

[1] F Bulos et al. "Some Fast Kicker Magnet Systems at SLAC:" in Proc. of 1987 IEEE Particle Accel. Conf., Washinglon, D.C., March 1987.

[2] L. Bartelson et al., "Kicker for the SLC Electron Demping Ring," in Proc. of 1987 IEEE Particle Accel. Conf., Washington DC. March 1987. pp. 1582-4.

[3] T. Mattison et al., "Kicker Systems for the Stanford Linear Collide," in Particle Accelerators, vol. 30, pp. 115-20, 1990.

[4] T. Mattison et al., "Status of the SLC Damping Ring Kicker Systerns," these proceedings.

[5] T. Mattison et al., "Operational Experience with SLC Damping Ring Kicker Magnets," these proceedings.

[6] G. Gross et al., "Development of Epaxy Pouting for High Voltage Insulation at SLAC," these proceedings.

[7] T. Matlison et al., "Pulse Shape Adjustment for the SLC Damping Ring Kickers," these proceedings.

[8] R. Cassel and M. Nguyen, "Kicker Pulsed Charger", these proceedings.

[9] J. Peller, "Improved High Voltage Coax for Antiproton Source Kicker Pulse Forming Networks and Pulse Transmission", Fermi National Acceicralor Laboralory.

[10] C.A. Frosi and D.B. Westenhaver, "Effects o[ Coaxial Cables on Fast-Risetime, High-Voltage Pulses". Joint EMP Technical Mecting, First Annual Nuclear EMP Meeting, 1973.

[11] W.J. Sarjcant and R.E. Dollinger. "High Power Electronjes". Tob Books, Inc, Blwe Ridge Summit, PA, pP, 171-180, 1989.

[12] E. Kuftel and W:S. Zaengl, "High Voltage Engineering", Pergamon Press, NY, NY, pp. 371, 1986.

[13] R. Bartrikas and E.J. McMahon, "Enginecring Dielectrics, Vol. I. Corona Measurcment and Interpretation". ASTM STP 669. 1979.

[14] U.S. Military Specification, MIL-C-17F, January 1983. 


\title{
DISCLAIMER
}

\begin{abstract}
This report was prepared as an account of work sponsored by an agency of the Uniled States Governument. Neither the United States Government nor any agency thereof, nor any of hoir employees, makes any warranty, express or implied, or assumes any legal liability or responsjWility for the accuracy, completeness, or usefuluess of any information, apparalus, product, or process disclosed, of represents that its use would not infringe privately owned rights. Reference herein to any specific commetcial product. prosess, of sovice by trede name, tradematk. manufacturer, or otherwise does not uecessarily constitute or imply its endoracment, recoummeidation, or favorins by the Uaited States Government or any agency thereof. The views and opinions of authors expressed berein do not necessarily state or reflect those of the United States Government or any agency thereof.
\end{abstract}

